\title{
The people's attitudes towards global environmental phenomena: a case study
}

\author{
Luis E. González*, Pablo da Silveira \\ CIFRA (González, Raga \& Asociados), Alejandro Chucarro 1152, 11300 Montevideo, Uruguay
}

\begin{abstract}
This study addresses the awareness and attitudes of Uruguayans towards global environmental phenomena, with particular emphasis on climate change. The environmental and climatic changes most clearly sensed by people, the main sources of information for the public on these subjects and the perception of the effectiveness of individual action in facing the adverse effects of these phenomena are assessed. This analysis is intended to contribute to the design of communication and public awareness strategies, either for the dissemination of specific subjects or for the communication of more general policies. Thus, assessing the possibility of improving communication capabilities and public outreach is deemed more relevant than evaluating whether public knowledge is or is not correct. The communication of appropriate information in order to correct wrong perceptions could be included, eventually, as part of the the effort to improve public outreach. The results of the study demonstrate the great weight of radio and television as sources of information on environmental changes. They also point out the increasing role of educational institutions in the dissemination of knowledge about this issue, confirm that the confidence in the effectiveness of individual action is strongly related to the access to information, and suggest that the local milieu may be especially important for stimulating people's awareness and action on these subjects.
\end{abstract}

KEY WORDS: Global environmental changes . Climate change - Public opinion - Environment . Environmental policies

\section{INTRODUCTION}

The results of a study on the awareness, attitudes and opinions of the urban population in Uruguay with regard to climate changes and to the environment in general are presented in this paper. The goal of this study is to assess how people perceive climatic and environmental changes and eventually react to them, rather than to discuss those issues per se.

The opinions and attitudes of the people in general (that is to say of the non-experts) on these matters are not very precise. They include more or less implicit judgements which the experts consider wrong and which may be fairly inconsistent among themselves. In other words, from an 'objective' point of view, public opinion in general can be a poor picture of reality. However, this situation is not a distinctive characteristic of public opinion on environmental subjects, as it is also observed with regard to other topics.

•E-mail: cifra@cifra.com.uy
Nevertheless, the study of public opinion on environmental and climatic changes is relevant since: (1) in many ways people's behaviour (which is obviously related to their opinion and attitudes) has a significant effect on the environment (waste recycling and energy saving are examples of this), and also (2) the political and actual feasibility of many policies relevant to this matter ultimately depends on the way in which people perceive them, which is in turn related to their general opinions and attitudes concerning these issues.

In brief, it is essential to learn about the state of public opinion with regard to the environmental and climatic changes in order to be able to act on them (Bruce et al. 1995). It is not possible, for instance, to design effective public awareness campaigns if the people's opinion is not known. Therefore, surveys of this type should be part of every assessment on environmental issues and should be able to provide information pertinent to the design of relevant policies.

In spite of the above, only a few systematic studies have been carried out from this perspective. Therefore, 
although in a strict sense the conclusions of this study can only be applied to Uruguay, any case study may contribute useful results and recommendations, either substantive or methodological.

It is worth keeping in mind, however, that the Uruguayan case has certain peculiarities, even within the Latin American framework. The country has a fairly homogeneous and small population (about 3150000 people, according to preliminary information from the 1996 census) distributed throughout a relatively small territory (as compared to other countries of the continent) of $176215 \mathrm{~km}^{2}$. As in the case of Argentina, social development indices show that the country has been fairly prosperous and 'modern' since relatively early times. This prvileged situation with respect to other countries of the region has remained. Costa Rica and Chile are the only other Latin American countries with social development indices similar to those of the countries located on the Río de la Plata.

\section{METHODOLOGY}

This study was carried out within the framework of the 'Uruguay Climate Change Country Study: Assessment of Climate Change Impacts in Uruguay' which was coordinated by the Comision Nacional sobre el Cambio Global. Most of the questions included in the survey were suggested by the study team. The idea of exploring the subject in general by assessing the people's awareness on specific phenomena was specially taken into account.

The data presented below resulted from a small set of questions included in a domestic urban survey known as an 'omnibus' survey in the professional terminology. This type of poll includes questions designed for different purposes and for different clients, and which follow certain internal consistency rules. This approach allows for the generation of a considerable volume of information at a relatively low cost.

The survey included a probabilistic household sam ple, designed on the basis of the sampling guidelines of the Instituto Nacional de Estadística. The individuals interviewed ( 1 per household) were selected according to predetermined quotas of sex and age. The quotas are based on the actual weight of the different groups within the population considered. A total of 1203 individuals aged 15 or older, randomly selected from cities and towns with a population over 10000 inhabitants, were personally interviewed. The survey was carried out in October 1995.

This type of sampling design is not, therefore, solely probabilistic. Actually, most general professional and consultancy work is based on non-probabilistic surveys with different types of sampling designs. This method has proved to be consistently effective in Uruguay in pre-electoral polls as well as for market research (especially regarding mass consumption products), which provides outputs that can be compared with actual sale figures independently from survey results.

In accordance with these criteria, the sample is representative of $3 / 4$ of the urban population of the country. An error margin of $\pm 2.5 \%$ (in relation to the total population under study) is deemed acceptable for this type of sampling design under tolerable confidence levels.

\section{RESULTS AND DISCUSSION}

\subsection{Awareness of environmental changes}

The environmental change phenomenon most widely known by the Uruguayans is the depletion of the ozone layer (usually referred to as the 'ozone hole' $\}$. This phenomenon is mentioned by $92 \%$ of the individuals interviewed, against $8 \%$ who indicate that they have never heard about it (Table 1). Three other phenomena are also considered very familiar, namely climatic variations such as flooding and droughts (mentioned by $90 \%$ of the individuals), animal and plant species extinction (known by $85 \%$ ), and deforestation ( $82 \%)$

On the contrary, other phenomena of great importance are relatively little known. Such is the case for sea-level rise (61\%), 'El Niño' (48\%) and the greenhouse effect $(44 \%)$

The variations in the response levels make it difficult to ascertain the degree of knowledge on global change. Does an overall awareness of these changes exist, or is the public only aware of some isolated phenomena which have been particularly disseminated, such as the depletion of the ozone layer?

As a first step towards answering this question a typology based on the total number of phenomena known by each individual interviewed was developed. It was observed that the 7 phenomena mentioned

Table 1. Awareness of different climatic phenomena. Urban areas, October 1995 (in \%)

\begin{tabular}{lcc} 
Have you heard about...? & Have heard & Haven't heard \\
\hline The ozone hole & 92 & 8 \\
Climatic variations & 90 & 10 \\
Species extinction & 85 & 15 \\
Deforestation & 82 & 18 \\
Sea level rise & 61 & 39 \\
El Nino & 48 & 52 \\
Greenhouse effect & 44 & 56
\end{tabular}


Table 2. Number of climatic phenomena (out of the 7 phenomena listed in Table 1) known by the individuals interviewed. Urban areas, October 1995 (in \%)

\begin{tabular}{|cc|}
\hline No. of phenomena known & $\%$ of interviewees \\
\hline All & 22 \\
5 or 6 & 46 \\
4 or less & 32 \\
& Total: 100 \\
\hline
\end{tabular}

above are jointly known by $22 \%$ of the Uruguayans, $46 \%$ of the people have heard about 5 or 6 , and the remaining $32 \%$ know about 4 or less.

Having heard about several phenomena of this nature does not necessarily imply a more or less precise knowledge about them. It is, however, reasonable to assume that, on average, those who have heard about a higher number of phenomena also know more about global change issues. In general, it is observed that the majority of Uruguayans are fairly well informed about the subject: $68 \%$ of the population have heard about at least 5 out of the 7 phenomena mentioned.

\subsection{The distribution of information}

As expected, the information about environmental changes is not homogeneously distributed among the population. While some sectors are widely informed, others hardly have elementary information. Which factors have a larger influence on the awareness of these phenomena?

The level of formal education seems to have the largest influence as regards the access to information. The more highly educated people have heard more frequently about these issues than the less educated. The differences are not very significant for the bestknown phenomenon (the depletion of the ozone layer), but become remarkable for the less widely disseminated issues. While $79 \%$ of the people who have undergone at least some university study have heard about the greenhouse effect, only $24 \%$ of the individuals who have not completed primary school have done so (Table 3).

Table 4 displays information on the number of phenomena known according to the socio-demographic characteristics of the people interviewed. The data indicate that people living in the capital city, Montevideo, are better informed than the rest of the population of the country. With regard to the socioeconomic level, $38 \%$ of the people from high and upper-middle sectors (less than $1 / 5$ of the population) are very well informed. In contrast, only $11 \%$ of the people from the
Table 3. Awareness on different climatic phenomena according to educational level. Urban areas, October 1995. Values represent the percentage of each educational category that has heard about the respective phenomena considered

\begin{tabular}{|lcccc|}
\hline & Primary & Secondary & University & $\begin{array}{c}\text { All } \\
\text { levels }\end{array}$ \\
\hline The ozone hole & 83 & 97 & 100 & 92 \\
Climatic variations & 85 & 93 & 99 & 90 \\
Species extinction & 72 & 93 & 98 & 85 \\
Deforestation & 70 & 89 & 97 & 82 \\
Sea level rise & 48 & 64 & 86 & 61 \\
El Niño & 38 & 49 & 72 & 48 \\
Greenhouse effect & 24 & 52 & 79 & 44 \\
\hline
\end{tabular}

Table 4. Number of climatic phenomena known by the individuals interviewed according to several socio-demographic indicators. Urban areas, October 1995 (in \%)

\begin{tabular}{|lccc|}
\hline & All & 5 to 6 & 4 or less \\
\hline All individuals & 22 & 46 & 32 \\
Location & & & \\
Montevideo & 26 & 46 & 28 \\
Other & 18 & 45 & 37 \\
Education & & & \\
Primary & 10 & 40 & 50 \\
Secondary & 24 & 54 & 22 \\
University & 60 & 34 & 6 \\
Age & & & \\
15 to 19 & 11 & 58 & 31 \\
20 to 29 & 19 & 53 & 28 \\
30 to 39 & 29 & 47 & 24 \\
40 to 64 & 27 & 43 & 30 \\
Over 64 & 17 & 34 & 49 \\
Socioeconomic level & & & \\
High and middle-high & 38 & 44 & 18 \\
Middle & 26 & 49 & 25 \\
Middle-low and low & 11 & 43 & 46 \\
Interest in politics & & & \\
Very interested & 38 & 50 & 12 \\
Quite interested & 38 & 46 & 16 \\
Not much interest & 16 & 52 & 32 \\
Not interested & 14 & 36 & 50 \\
& & & \\
\hline
\end{tabular}

lower-middle and low sectors (approximately $2 / 5$ of the population) are similarly well informed.

The level of information is also related to the people's attitudes towards politics: individuals who are very or fairly interested in politics are the best informed about environmental and climatic changes. The interest in politics seems to be linked to a broader interest in 'the surrounding world'. Although it is also related to education, it is not solely dependent on it (Schneider 1993).

The most influential single factor is formal education. About $60 \%$ of the individuals with some kind of university education have heard about all of the phe- 
nomena, but only $10 \%$ of those who have only attended primary school have done so. On the other hand, just $6 \%$ of the most educated have heard about only 4 or less of the phenomena. This percentage increases to $50 \%$ for those who have only reached primary school level.

\subsection{Main sources of information}

Since the best informed people are those who have been exposed to formal education, it could be assumed that school is the place where most information about global environmental changes is acquired.

However, that is not true. The main sources of information about environmental changes are the mass media. Three out of four Uruguayans have become aware of these problems through radio or television. The press ranks far below in importance, appearing as the main source of information for only 1 out of 10 of the individuals interviewed. Other sources (books, scientific publications, conferences) taken together only reach $5 \%$ of the population.

According to the survey data, educational institutions only play a minor role in the dissemination of information on environmental changes. Only $3 \%$ of the people interviewed mentioned them as the main information source. However, this result may be misleading

As indicated earlier, only people aged 15 or older were interviewed. The majority of the people surveyed were at least $40 \mathrm{yr}$ old. Consequently, most of them attended school at a time when environmental topics were not included in the educational agenda. The survey itself provides some insight on how much the situation has changed in recent years: $17 \%$ of the youngest individuals ( 15 to $19 \mathrm{yr}$ ) indicate that the educational institutions are their main source of information, while very few of the people older than 19 (0) to $3 \%$ ) provide the same answer.

Television and radio are particularly important sources of information among people with less formal education (González Requena 1992). More than 80\% of the individuals who have only attended primary school have heard about environmental changes on radio and TV. In contrast, only $55 \%$ of the people having university education regard these media as their main source of information. The incidence of scientific publications increases among the most educated (9\%) as does that of books $(6 \%)$ and conferences $(5 \%)$.

Further, the higher the awareness of these phenomena, the more diverse the sources of information are. Consequently, the relative weight of radio and TV is reduced. While $74 \%$ of the individuals who know about up to $A$ phenomena have received information mainly through the media, only $63 \%$ of those who know about all the phenomena mentioned have done so. The written press has the highest weight among the latter group: $21 \%$ receive information from newspapers and magazines, $5 \%$ from scientific publications and $4 \%$ from books (Table 5 ).

\subsection{A list of concerns}

The opinion of Uruguayans regarding the changes which can most affect people's lives is related to their degree of awareness of the different phenomena addressed. In brief, Uruguayans tend to think that the most serious phenomena are the ones which they have heard the most about, and minimize the impacts of other phenomena which are less familiar to them.

For instance, the depletion of the ozone layer (which is the phenomenon most widely known) is mentioned by $62 \%$ of the individuals interviewed as the event which can most affect people's lives. In contrast, the greenhouse effect (the phenomenon least known to the public, although one that experts are highly concerned about) is only mentioned by $9 \%$.

Residents of cities and towns other than the capital, as well as the youngest people, are the most concerned about the ozone hole. This is probably because, in the short term, they are the most exposed to its effects. In contrast - and even though it is the issue which raises most concern among all groups - the ozone hole is relatively less worrying for those who are better educated and informed about global change. Only $52 \%$ of the best-informed people mention ozone depletion, while $22 \%$ point to the greenhouse effect and $12 \%$ to deforestation as the phenomenon which can most affect people's life (Table 6).

\subsection{Personal attitudes towards environmental changes}

The information received by Uruguayans regarding environmental changes does not seem to be leading them to a fatalistic attitude: almost $70 \%$ of the people believe that their personal behaviour 'may help to counteract the adverse effects of these phenomena'. The most-educated people and, consequently, the best informed, are the most convinced about the relevance of individual actions. About $81 \%$ of the most educated (those with at least some university level studies) and only $58 \%$ of the less educated (primary level) think that way. Similarly, $83 \%$ of the best informed (those who have heard about all of the phenomena mentioned) believe in the potentially positive effects of their own behaviour. However, only $49 \%$ of the less informed share this opinion. 
Table 5. Main sources of information on climatic phenomena. Urban areas, October 1995 (in \%). DNK, DNA: doesn't know, doesn't answer

\begin{tabular}{|c|c|c|c|c|c|c|c|c|}
\hline & $\begin{array}{l}\text { Radio, } \\
\text { TV }\end{array}$ & $\begin{array}{c}\text { Newspapers, } \\
\text { magazines }\end{array}$ & Books & $\begin{array}{c}\text { Scientific } \\
\text { publications }\end{array}$ & Conferences & $\begin{array}{l}\text { Educational } \\
\text { institutions }\end{array}$ & $\begin{array}{l}\text { Friends, } \\
\text { relatives }\end{array}$ & DNK, DNA \\
\hline All individuals & 74 & 12 & 2 & 2 & 1 & 3 & 3 & 4 \\
\hline \multicolumn{9}{|l|}{ Location } \\
\hline Montevideo & 69 & 15 & 2 & 2 & 1 & 4 & 2 & 5 \\
\hline Other & 80 & 8 & 1 & 1 & 1 & 2 & 5 & 3 \\
\hline \multicolumn{9}{|l|}{ Education } \\
\hline Primary & 78 & 8 & 1 & 0 & 0 & 0 & 5 & 8 \\
\hline Secondary & 75 & 14 & 1 & 1 & 0 & 5 & 2 & 2 \\
\hline University & 54 & 18 & 6 & 9 & 5 & 5 & 1 & 2 \\
\hline \multicolumn{9}{|l|}{ Age } \\
\hline 15 to 19 & 65 & 10 & 4 & 1 & 0 & 17 & 4 & 0 \\
\hline 20 to 29 & 79 & 9 & 1 & 2 & 1 & 3 & 2 & 3 \\
\hline 30 to 39 & 73 & 13 & 2 & 3 & 2 & 3 & 4 & 0 \\
\hline 40 to 64 & 74 & 14 & 1 & 2 & 1 & 1 & 3 & 4 \\
\hline Over 64 & 73 & 10 & 2 & 0 & 0 & 0 & 4 & 11 \\
\hline \multicolumn{9}{|c|}{ No. of phenomena known } \\
\hline All & 63 & 21 & 4 & 5 & 3 & 3 & 1 & - \\
\hline 5 to 6 & 79 & 11 & 2 & 1 & - & 4 & 2 & 1 \\
\hline 4 or less & 74 & 6 & - & - & - & 1 & 6 & 13 \\
\hline
\end{tabular}

Table 6. Which climatic phenomenon is considered to most affect people's lives (first mention only). Urban areas, October 1995 (in \%). DNK, DNA: doesn't know, doesn't answer

\begin{tabular}{|c|c|c|c|c|c|c|c|c|c|}
\hline & $\begin{array}{l}\text { Ozone } \\
\text { hole }\end{array}$ & $\begin{array}{c}\text { Greenhouse } \\
\text { effect }\end{array}$ & $\begin{array}{l}\text { Deforest- } \\
\text { ation }\end{array}$ & $\begin{array}{c}\text { Climatic } \\
\text { variations }\end{array}$ & El Nin̄o & $\begin{array}{l}\text { Species } \\
\text { extinction }\end{array}$ & $\begin{array}{l}\text { Sea-level } \\
\text { rise }\end{array}$ & None & DNK, DNA \\
\hline All individuals & 62 & 9 & 8 & 6 & 2 & 2 & 1 & 1 & 9 \\
\hline \multicolumn{10}{|l|}{ Location } \\
\hline Montevideo & 57 & 10 & 11 & 6 & 2 & 2 & 0 & 1 & 11 \\
\hline Other & 68 & 8 & 5 & 6 & 2 & 2 & 1 & 1 & 7 \\
\hline \multicolumn{10}{|l|}{ Education } \\
\hline Primary & 60 & 6 & 5 & 9 & 2 & 1 & 1 & 3 & 13 \\
\hline Secondary & 67 & 9 & 10 & 4 & 2 & 3 & 0 & 0 & 5 \\
\hline University & 50 & 22 & 12 & 5 & 3 & 2 & 1 & 0 & 5 \\
\hline \multicolumn{10}{|l|}{ Age } \\
\hline 15 to 19 & 66 & 7 & 9 & 7 & 3 & 3 & 0 & 1 & 3 \\
\hline 20 to 29 & 69 & 9 & 6 & 4 & 2 & 3 & 0 & 1 & 6 \\
\hline 30 to 39 & 64 & 10 & 10 & 6 & 2 & 2 & 1 & 0 & 5 \\
\hline 40 to 64 & 61 & 12 & 8 & 6 & 1 & 2 & 1 & 1 & 8 \\
\hline Over 65 & 51 & 6 & 9 & 8 & 2 & 1 & 0 & 4 & 20 \\
\hline \multicolumn{10}{|c|}{ No. of phenomena known } \\
\hline All & 52 & 22 & 12 & 6 & 3 & 2 & - & - & 3 \\
\hline 5 to 6 & 69 & 9 & 9 & 4 & 1 & 2 & 1 & - & 5 \\
\hline 4 or less & 58 & 1 & 5 & 10 & 2 & 2 & - & 4 & 18 \\
\hline
\end{tabular}

There is also a high correlation between confidence in personal action and interest in politics. Eighty-five percent of the people who are very interested in politics believe that their personal behaviour 'can make a difference' in this matter. As the interest in politics decreases, so does the confidence in the effectiveness of individual actions.
The most remarkable result, however, is that people living in urban areas other than Montevideo are more confident in the effectiveness of individual actions, at least with regard to these subjects, than Montevideo residents (given comparable information and educational levels). This fact is particularly striking since, as mentioned above, the people in Montevideo are, on 
Table 7. Do you think that your personal behavior can help to counteract the adverse effects of these phenomena? Urban areas, October 1995 (in \%). DNK, DNA: doesn't know, doesn't answer

\begin{tabular}{|lccc|}
\hline & Yes & No & DNK, DNA \\
\hline All individuals & 69 & 21 & 10 \\
Location & & & \\
Montevideo & 67 & 22 & 11 \\
Other & 72 & 19 & 9 \\
Education & & & \\
Primary & 58 & 26 & 16 \\
Secondary & 76 & 17 & 7 \\
University & 81 & 16 & 3 \\
Age & & & \\
15 to 19 & 67 & 24 & 9 \\
20 to 29 & 72 & 18 & 10 \\
30 to 39 & 80 & 15 & 5 \\
40 to 64 & 71 & 21 & 8 \\
over 64 & 52 & 27 & 21 \\
Interest in politics & & & \\
Very interested & 85 & 12 & 3 \\
Quite interested & 75 & 19 & 6 \\
Not much interest & 70 & 20 & 10 \\
Not interested & 57 & 26 & 17 \\
No. of phenomena known & & & \\
All & 83 & 13 & 4 \\
5 to 6 & 75 & 19 & 6 \\
4 or less & 49 & 29 & 22 \\
\hline
\end{tabular}

the average, better informed (and more educated) than the rest of the population. The scale of smaller cities is likely to enhance this feeling, since people have a better chance to influence their milieu than in the case of larger environments.

\section{CONCLUSIONS}

Based on knowledge about people's perception of environmental and climatic changes, important conclusions can be drawn which are useful both for the organization of communication and public awareness campaigns on these subjects and for the design and implementation of relevant policies.

(1) Firstly, the importance of electronic media (radio and TV) as mass communication tools (Rodrigo Alsina 1993 ) is confirmed. Not only are they the media which can reach the largest number of people, but they also seem to be reasonably effective for conveying certain messages to the bulk of the population

(2) The importance of these media is reinforced if a second conclusion of this study is taken into account: the people who have been less exposed to formal education are also the least informed about environmental issues. Therefore, these sectors should be particularly considered if the aim is to improve awareness of the general public regarding the issues. Radio and TV appear to be the best media for approaching these audiences.

(3) The use of other media becomes important when the purpose of the campaign is to improve people's knowledge on enviromental issues rather than just promote public awareness. The press, which is normally considered the most appropriate means of conveying relatively complex messages, has a good outreach among middle and highly educated people (those who can act as opinion leaders in these subjects).

The results obtained also indicate that the educational system may be very appropriate for reaching the younger audiences. This could be observed even though the study was not designed to analyze the importance of the educational system for the dissemination of environmental issues, and even though most of the people receiving information on such issues through formal education (those 15 years old or younger) were not included in the survey sample, since environmental topics were incorporated into the educational agenda only very recently.

(4) Finally, the results indicate that people living in small cities are more confident about the effectiveness of their personal actions than people living in the capital city (even if those in small cities are less informed and less educated). This may be related to different day-to-day experiences due to the smaller scale of their urban milieu.

Should this conclusion be confirmed, communication and public action strategies should pay special attention to the 'local' scale and to those day-to-day events through which the influence of individual behaviour on the environment actually operates.

The 'one's own road' experiences carried out in developed countries (referring to a segment of a road which local organizations 'adopt', becoming reponsible for their maintenance) are a good example of this approach.

This type of strategy is easier to apply in small urban areas, but it can also be implemented in relatively large cities (such as Montevideo) as long as it is organized at a local scale (neighbourhoods).

\section{LITERATURE CITED}

Bruce J, Lee J, Haites E (eds) (1995) Economic and social dimensions of climate change. Contribution of Working Group III to the Second Assessment Report of the Intergovernmental Panel on Climate Change. Cambridge University Press, Cambridge

González Requena J (1992) El discurso televisivo. Cátedra, Madrid

Rodrigo Alsina M (1993) La construcción de la noticia. Paidós, Barcelona

Schneider H (ed) (1993) Environmental education: an approach to sustainable development. OCDE, Paris 